\title{
A palladium-hinged organometallic square with a perfect-sized cavity for the encapsulation of three heteroguests
}

Received 00th January 20xx, Accepted 00th January 20xx

DOI: $10.1039 / x 0 x \times 00000 x$

\author{
Víctor Martínez-Agramunt ${ }^{\mathrm{a}}$ and E. Peris ${ }^{\mathrm{a*}}$
}

\begin{abstract}
A nanometer-sized tetrapalladium metallosquare with a pyrene-bisimidazolylidene ligand was found to display a perfectsized cavity for the encapsulation of three heteroguests, enabling the formation of quintuple D-A-D-A-D stacks. The encapsulating properties of the metallosquare are clearly determined by the presence of the pyrene panels, which endow the metallosquare a three-dimensional shape, and also behaves as an effective antenna for for $\pi$-stacking interactions.
\end{abstract}

Supramolecular systems with cavities, capable of hosting molecular guests have received great attention due to their potential applications as flasks for chemical reactions, ${ }^{1}$ containers for reactive chemical species, ${ }^{2}$ hosts for aromatic stacks, ${ }^{3}$ sensors, ${ }^{4}$ and as transport vehicles for molecules with medical properties. ${ }^{5}$ While many supramolecular systems are able to encapsulate single guests, the binding of multiple guests by a single receptor can lead to new modes of host-guest interactions that may be translated into new applications. ${ }^{6}$ Enabling artificial systems in which the binding of one substrate cooperatively affects the binding of subsequent guest molecules, and promotes allosteric communication between all components, is one of the greatest challenges of supramolecular chemistry. In addition, supramolecular entities with cavities of the appropriate size can be used to approach substrates closer by encapsulation, so that their mutual interaction can exhibit unusual or non-classical physical properties. $^{3 c}$ For example, receptors capable of intercalating multiple stacks are very challenging, ${ }^{3 b}$ because enabling discrete $\pi$-stacks can facilitate the study of the charge transport at the molecular level, a long-standing issue for the design of nanoscale electronic devices. ${ }^{3 a, 3 d, 7}$

In general, the most efficient tool for enabling discrete aromatic stacks in solution is the use of organic-pillared co-facial coordination cages, normally displaying a trigonal prismatic shape, ${ }^{3 a}, 3 d, 7$ in which the number of planar guest molecules depends exclusively on the cavity height, which is determined by the pillar length. Inspired by the pioneering works by Hahn and co-workers that described the preparation of a series of square-like and rectangle like metallo-cages using a benzo-bisimidazolylidene ligand, ${ }^{8}$ we recently described two nickel-

Institute of Advanced Materials (INAM), Universitat Jaume I, Av. Vicente Sos Baynat $s / n, 12071$-Castellón, Spain.

Electronic Supplementary Information (ESI) available: Experimental procedure, NMR, Uv-Vis and Mass spectra. All titration data and determination of binding constants. hinged molecular rectangles that were used for the encapsulation of polycyclic aromatic hydrocarbons (PAHs) (Scheme 1). ${ }^{9}$ These molecular receptors, were based on a pyrene-bis-imidazolylidene ligand, in combination with pyrazine $\left([1]^{4+}\right)$ or $4,4^{\prime}$-bipyridine $\left([2]^{4+}\right)$. Due to their different dimensions, the rectangle with the pyrazine pillars was able to accommodate only one PAH molecule, while the one with the longer by-pyridine, was capable of hosting up to two guest molecules (Scheme 1). By using the same pyrene-bisimidazolylidene ligand, we also described a palladium-cornered metallosquare $[3]^{4+}$, whose cavity was suitable for the encapsulation of fullerenes. ${ }^{10}$ This metallosquare displays a metal-to-metal distance of $13 \AA$, approximately four times the distance for an effective $\pi-\pi$ stacking interaction, and therefore is expected to be suitable for inclusion of up to three polyaromatic guests.

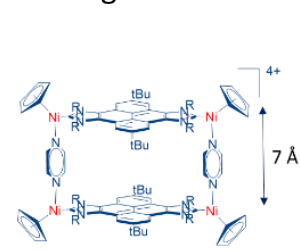

$[1]^{4+}$

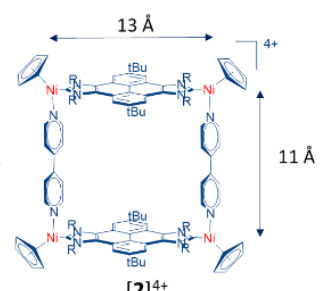

$[2]^{4+}$

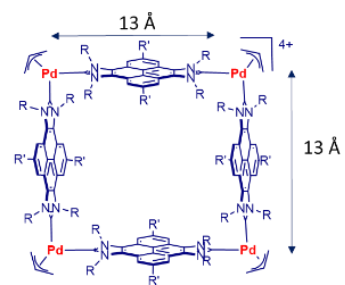

$[3]^{4-}$ Scheme 1. Metallorectangles $\left([\mathbf{1}]^{4+}\right.$ and $\left.[\mathbf{2}]^{4+}\right)$ and metallosquare $[\mathbf{3}]^{4+}$ previously
described in our group.

With these precedents in hand, in this work we examined the host-guest chemistry properties of the metallosquare 3 with a series of PAHs. In addition, we also studied the ability of $\mathbf{3}$ to 
accommodate two different aromatic guests. As will be discussed, the $\pi$-stacks are ordered in donor-acceptor-donoracceptor-donor (D-A-D-A-D) arrays, with the electron-rich pyrene fragments of the di-NHC ligand as bookend donors.

We first tested the molecular square [3] $\left(\mathrm{BF}_{4}\right)_{4}$ for the recognition of pyrene and triphenylene. The host-guest properties of the square were studied by ${ }^{1} \mathrm{HNMR}$ spectroscopy, by monitoring the changes produced in the chemical shifts of the signals due to the ligands of the metal complex upon addition of solutions with the two aromatic guests. The experiments were carried out in $\mathrm{CD}_{3} \mathrm{CN}$, at room temperature and at a constant concentration of host, typically $1 \mathrm{mM}$. For both titrations, the addition of the solutions of the guests produced important perturbations in the chemical shifts of the signals of the host, indicating the formation of inclusion complexes that showed fast kinetics on the NMR timescale. As an illustrative example, Figure 1 shows the aromatic region of the ${ }^{1} \mathrm{H}$ NMR spectra acquired during the titration of $[3]\left(\mathrm{BF}_{4}\right)_{4}$ with pyrene. The sequence of spectra shows how the resonances due to the protons of the pyrene fragment of the pyrene-bisimidazolylidene ligands of the molecular square are upfield shifted upon the addition of the pyrene solution. The determination of the association constant was performed by nonlinear analysis of the titration data. The binding isotherm resulting from plotting the variation of the chemical shift with the guest/host ratio was bet fitted to a 1:2 host:guest stoichiometry, as a result from the analysis of the distribution of the residuals compared to a 1:1 stoichiometry. The analysis of the ${ }^{1} \mathrm{H}$ NMR spectra also allowed determining the host:guest association constants for the titrations performed with pyrene $\left(\mathrm{K}_{11}=220(20) \mathrm{M}^{-1} ; \mathrm{K}_{12}=46(3) \mathrm{M}^{-1}\right)$ and triphenylene $\left(\mathrm{K}_{11}\right.$ $\left.=280(30) \mathrm{M}^{-1} ; \mathrm{K}_{12}=52(4) \mathrm{M}^{-1}\right)$.
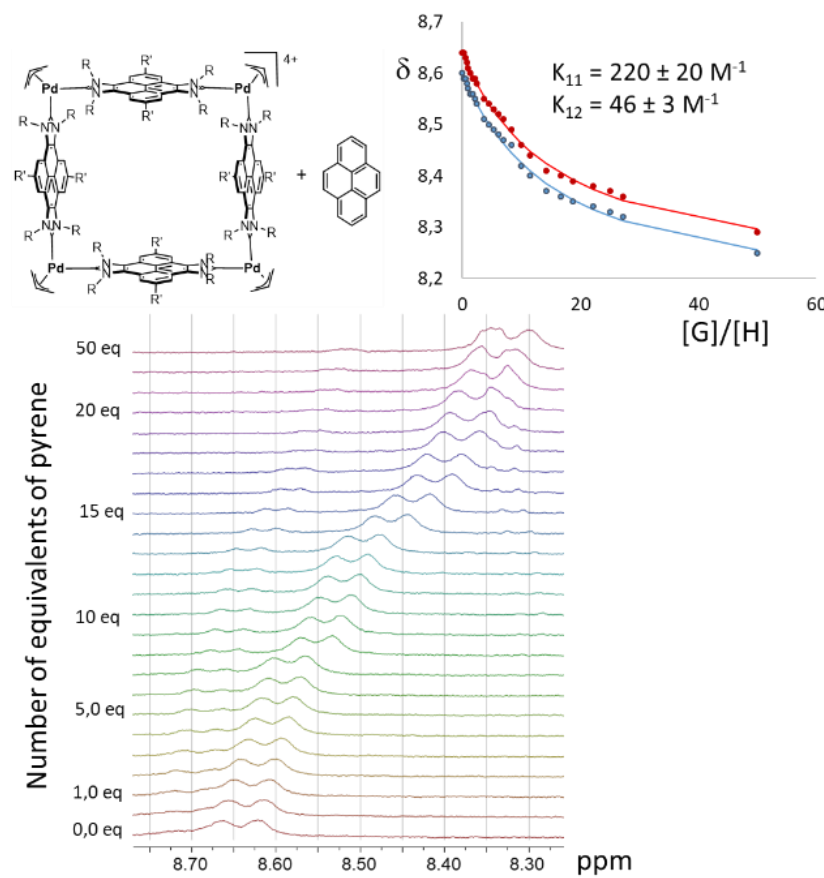

Figure 1. Representative region of the ${ }^{1} \mathrm{H}$ NMR $(400 \mathrm{MHz})$ spectra of the titration of [3] $\left(\mathrm{BF}_{4}\right)_{4}$ with pyrene in $\mathrm{CD}_{3} \mathrm{CN}$. The spectra were recorded at a constant concentration of $[3]\left(\mathrm{BF}_{4}\right)_{4}(1 \mathrm{mM})$. The plot represents the binding isotherm, with the resulting association constants obtained from the nonlinear regression
The analysis of the binding affinity of coronene could not be performed by ${ }^{1} \mathrm{H}$ NMR titrations due to the low solubility of this guest in $\mathrm{CD}_{3} \mathrm{CN}$. Therefore, for the determination of the binding constant with this PAH molecule, we decided to perform Uv-Vis titrations. The Uv-Vis spectrum of [3] $\left(\mathrm{BF}_{4}\right)_{4}$ shows the bands due to the absorption of the pyrene moieties of the bridging ligands of the complex between 300 and $370 \mathrm{~nm}$. Upon addition of coronene, the intensities of the bands at 323, 334, 339 and 345 $\mathrm{nm}$ increase, while the band at $354 \mathrm{~nm}$ becomes less intense, thus showing a clear isosbestic point at $348 \mathrm{~nm}$ (see Figure 2). A second isosbestic point can also be observed at $368 \mathrm{~nm}$. The changes in the absorbances were found to give saturation upon addition of 8 equivalents of the guest. Based on the changes observed, the binding constants were determined using a global fitting analysis. ${ }^{11}$ Again, we found that the best fit was obtained when we used a 1:2 H:G stoichiometric model, which allowed us to obtain the association constants for the formation of the $1: 1$ and $1: 2 \mathrm{H}: \mathrm{G}$ complexes. The values obtained were $\mathrm{K}_{11}=$ $5.0(8) \times 10^{4} \mathrm{M}^{-1}$, and $\mathrm{K}_{12}=7.4(4) \times 10^{3} \mathrm{M}^{-1}$.

The association constants that we obtained for the three PAH guests under study were in the order pyrene < triphenylene $<<$ coronene, indicating that as the guest becomes more $\pi$ electron-rich, the $\pi-\pi$-stacking interaction between the guest and the host becomes more effective, and therefore the binding constant becomes larger. ${ }^{9,12}$

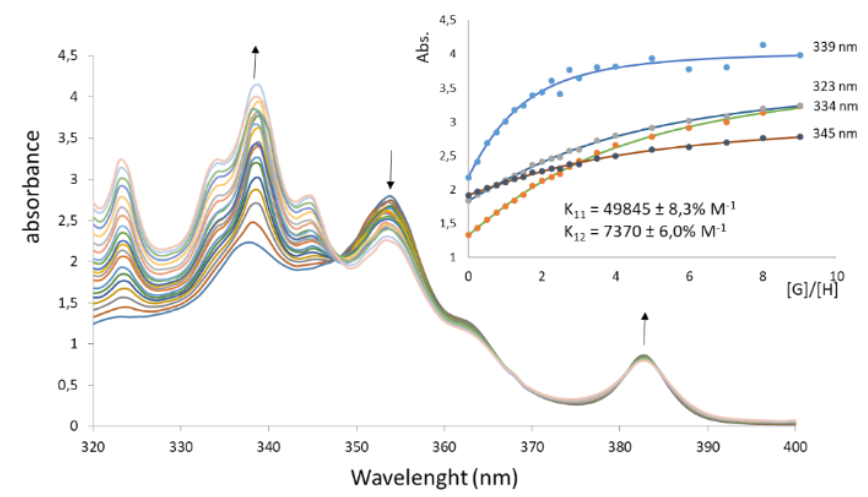

Figure 2. Uv-Vis. spectra acquired during the titration of $[3]\left(\mathrm{BF}_{4}\right)_{4}\left(3 \times 10^{-5} \mathrm{M}\right)$ with of the bands at $339,323,334$ and $345 \mathrm{~nm}$ against the [coronene]/[3] ([G]/[H]) ratio.

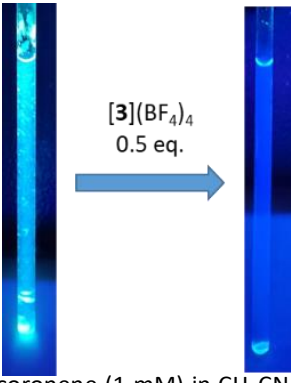

Figure 3. A sample of coronene (1 $\mathrm{mM}$ ) in $\mathrm{CH}_{3} \mathrm{CN}$ irradiated with UV light before (left) and after (right) adding 0.5 equivalents of $[3]\left(\mathrm{BF}_{4}\right)$

Given the large association constant found for [3] $\left(\mathrm{BF}_{4}\right)_{4}$ with coronene, we tested the metallosquare as coronene scavenger in $\mathrm{CH}_{3} \mathrm{CN}$. For this experiment we prepared a $1 \mathrm{mM}$ solution of coronene in $\mathrm{CH}_{3} \mathrm{CN}$. The irradiation of this solution with UV light $(365 \mathrm{~nm})$ produces a strong emission due to the fluorescence properties of coronene. Then 0.5 equivalents of $[3]\left(\mathrm{BF}_{4}\right)_{4}$ was 
added, and the resulting solution resulted non-emissive upon irradiation with UV light, a clear indication that coronene was encapsulated within the metallosquare (Figure 3 ).

Once the ability of $[3]\left(\mathrm{BF}_{4}\right)_{4}$ to encapsulate several polycyclic aromatic hydrocarbons was proved, we decided to see if we could enforce the trapping of three guests. For the design of effective aromatic stacks, it is important to consider that A-A and $D-A$ interactions are known to be more favorable than $D-D$ stacks. ${ }^{13}$ Taking this into account, we thought that the incorporation of the electron-poor $\mathrm{N}, \mathrm{N}^{\prime}$-dimethylnaphthalenetetracarboxy diimide (NTCDI) as heteroguest, should favor the formation of D-A-D-A-D quintuple stacks by intercalating between the electron-rich PAH guests and the pyrene panels of the cage. The experiments were carried out by subsequently adding two equivalents of PAH (pyrene, triphenylene or coronene) and two equivalents of NTCDI to a solution of [3] $\left(\mathrm{BF}_{4}\right)_{4}$ in $\mathrm{CD}_{3} \mathrm{CN}$ (Scheme 2). The formation of the quintuple stacking structures was strongly supported by NMR spectroscopy and mass spectrometry. The High Resolution Mass Spectrometric (HRMS) studies of the mixtures, showed intense peaks at $\mathrm{m} / \mathrm{z} 988.5,964.0$ and 970.5 , for the mixtures of [3] $\left(\mathrm{BF}_{4}\right)_{4}$ with coronene, pyrene and triphenylene, respectively, which are assigned to $[3 \supset(\mathrm{PAH}+2 \mathrm{NTCDI})]^{4+}$. The formation of the same host:guest complex product could also be accomplished by inverting the order of addition of the guests (first NTCDI and then the PAH). As an illustrative example, Figure 4 shows the mass spectrum obtained for the mixture of $[3]\left(\mathrm{BF}_{4}\right)_{4}$ with NTCDI and coronene.

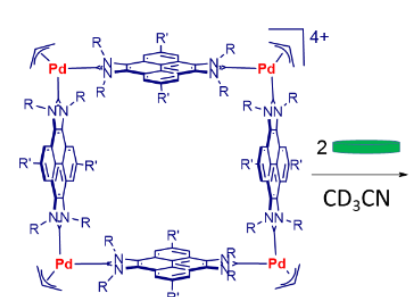

$[3]^{4+}$

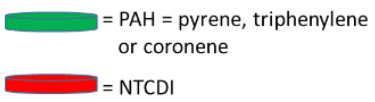

$=$ NTCDI

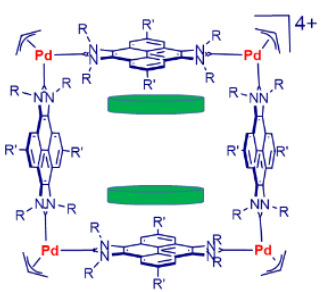

[3つ(2PAH) $]^{4+}$

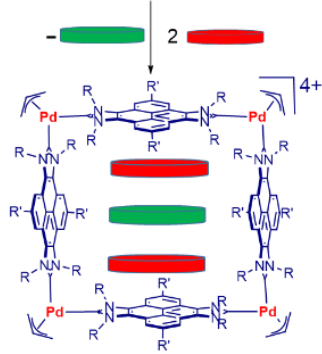

$[3 \supset(\mathrm{PAH}+2 \mathrm{NTCDI})]^{4+}$
Scheme 2. Sequential encapsulation of PAH and NTCDI into the cavity of the metallosquare $[3]^{4+}$.

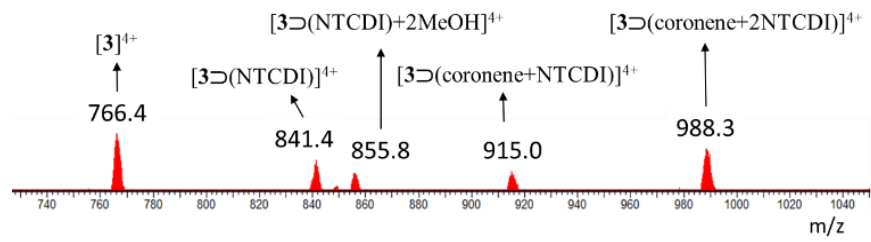

Figure 4. High Resolution Mass Spectrum (HRMS) of a mixture of [3](BF $)_{4}$ with coronene and NTCDI in $\mathrm{CH}_{3} \mathrm{CN}$ at $298 \mathrm{~K}$.

The quintuple stacking is also supported by NMR spectroscopy. As an illustrative example, Figure 5 shows a series of comparative spectra for the encapsulation of coronene and NTCDI in [3] $\left(\mathrm{BF}_{4}\right)_{4}$. The encapsulation of the heteroguests inside the cavity of $[3]\left(\mathrm{BF}_{4}\right)_{4}$ breaks the simmetry of the host, as evidenced by the appeareance of three separate sets of signals assigned to the protons of the vertical (two sets) and horizontal (one set) pyrene panels of the cage. A similar splitting is observed for the resonances due to the allyl protons and to the protons of the methylene group bound to the nitrogens of the imidazolylidenes. The fact that these changes can be observed by ${ }^{1} \mathrm{H}$ NMR spectroscopy at room temperature indicates that the site-exchange of guests in the host:guest complex is slow on the NMR timescale. The signals of both, coronene and NTCDI are strongly shifted upfield due to the encapsulation in the cavity of $3^{4+}$, and the integrals of the protons assigned to $3^{4+}$, coronene and NTCDI are in perfect agreement with a $3^{4+}$ :coronene:NTCDI ratio of $1: 1: 2$. The order of the D-A-D-A-D stacks is also confirmed by ${ }^{1} \mathrm{H}^{1}{ }^{1} \mathrm{H}$ ROESY NMR, which shows coupling between the signals due to the methyl group of NTCDI, and the signals due to the neighboring coronene (see ESI). The resonances due to the methyl group of NTCDI, also show ROESY coupling with the signals due to the protons of the methyl group of the tert-butyl moieties bound to the pyrene panels of the metallosquare. These observations are a clear indication that each molecule of NTCDI is sandwiched in between one molecule of coronene and one of the pyrene moieties of the metallosquare. Finally, the Diffusion Ordered NMR spectrum (DOSY) of $\left[3 \supset\right.$ (coronene+2NTCDI) ${ }^{4+}$ shows that all proton resonances display the same diffusion coefficient in $\mathrm{CD}_{3} \mathrm{CN}$ $\left(D=5.81 \times 10^{-10} \mathrm{~m}^{2} \mathrm{~s}^{-1}\right)$, indicating that all three molecules of guests are associated with the metallosquare forming a single assembly (see ESI). Similar conclusions can be derived from the analyses of the NMR studies carried out for $\left[3 \supset(\text { pyrene+2NTCDI) }]^{4+}\right.$, and $\left[3 \supset\right.$ (triphenylene+2NTCDI) ${ }^{4+}$ (see ESI for all details).

Figure 5. Selected region of the ${ }^{1} \mathrm{H}$ NMR spectra of a) $[3]\left(\mathrm{BF}_{4}\right)_{4}$, b) coronene, c) NTCDI, and d) $[3 \supset \text { (coronene+2NTCDI) }]^{4+}$. All spectra carried out in $\mathrm{CD}_{3} \mathrm{CN}$ at room

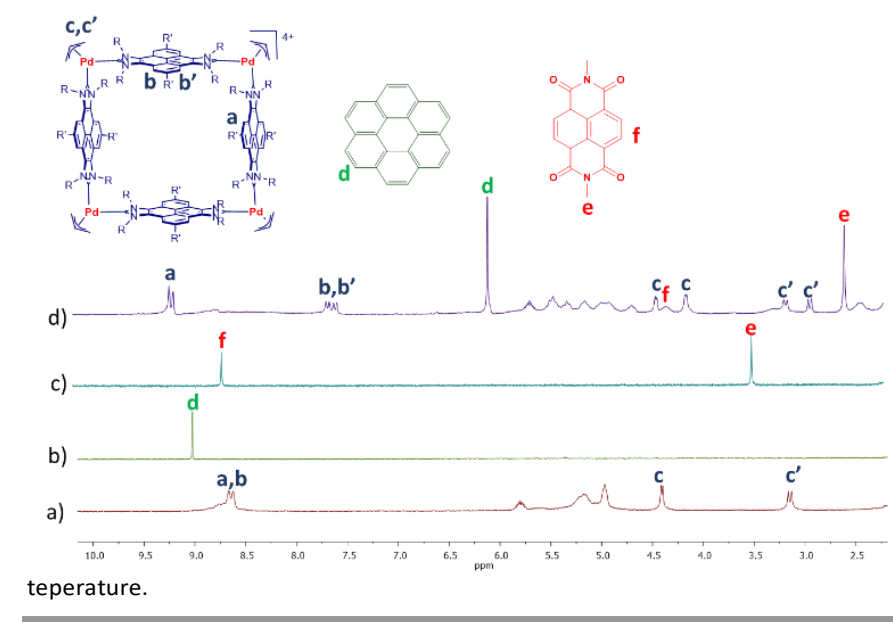

The formation of the quintuple-stacked supramolecular system was also studied by Uv-Vis- spectroscopy. The addition of two equivalents of NTCDI on a solution of [3] $\left(\mathrm{BF}_{4}\right)_{4}$ in $\mathrm{CH}_{3} \mathrm{CN}$ induced the appearance of a CT band at around $382 \mathrm{~nm}$. This band is redshifted compared to the weaker band shown by 'empty' 
[3] $\left(\mathrm{BF}_{4}\right)_{4}(376 \mathrm{~nm})$, most likely due to the formation of D-A stacks between the pyrene panels of the cage (D) and the NTCDI guest (A). Subsequent addition of coronene (or triphenylene) moves the absorption band back to $376 \mathrm{~nm}$, due to the incorporation of the molecule of coronene (or triphenylene) to the system forming a D-A-D-A-D stack. In this quintuple stack the charge transfer probably goes mainly from the molecule of coronene (or triphenylene) to NTCDI, thus reducing the participation of the pyrene panels in the CT process, which should explain why the absorption band due to pyrene moves back to $376 \mathrm{~nm}$ (see Figures S39 and S40 in ESI).

In conclusion, we found that our organometallic-based metallosquare displays a perfect size for the effective encapsulation of three large $\pi$-conjugated heteroguests, enabling the formation of quintuple D-A-D-A-D stacks. Unlike any other metallosupramolecular systems previously used for the encapsulation of multiple heteroguests, our system is the first one to show a square structure, while all other known examples are based on 'closed' trigonal prismatic architectures. Given the large number of Janus di-NHC ligands connected by large $\pi$-conjugated systems that we have prepared in our lab during the last few years, we believe that we are in a priviledged position for desinging new metallosupramolecular templates for tailoring discrete $\pi$-stacks of varying heights and compositions. Enabling effective methods for achieving tailormade aromatic stacks is necessary to enrich our ability to manipulate material properties at the supramolecular level.

We gratefully acknowledge financial support from the Ministerio de Ciencia y Universidades (PGC2018-093382-B-I00) and the Universitat Jaume I (UJI-B2017-07). We are grateful to the Serveis Centrals d'Instrumentació Científica (SCIC-UJI) for providing with spectroscopic facilities.

\section{Notes and references}

1 a) M. Yoshizawa, J. K. Klosterman and M. Fujita, Angew. Chem. Int. Ed., 2009, 48, 3418-3438; b) S. H. A. M. Leenders, R. Gramage-Doria, B. de Bruin and J. N. H. Reek, Chem. Soc. Rev. 2015, 44, 433-448; c) J. Meeuwissen and J. N. H. Reek, Nat. Chem., 2010, 2, 615-621; d) T. S. Koblenz, J. Wassenaar and J. N. H. Reek, Chem. Soc. Rev., 2008, 37, 247-262; e) M. J. Wiester, P. A. Ulmann and C. A. Mirkin, Angew. Chem. Int. Ed., 2011, 50, 114-137.

2 a) S. Horiuchi, T. Murase and M. Fujita, J. Am. Chem. Soc., 2011, 133, 12445-12447; b) M. Kawano, Y. Kobayashi, T. Ozeki and M. Fujita, J. Am. Chem. Soc., 2006, 128, 6558-6559.

3 a) S. Fujii, T. Tada, Y. Komoto, T. Osuga, T. Murase, M. Fujita and M. Kiguchi, J. Am. Chem. Soc., 2015, 137, 5939-5947; b) J. K. Klosterman, Y. Yamauchi and M. Fujita, Chem. Soc. Rev., 2009, 38, 1714-1725; c) V. Maurizot, M. Yoshizawa, M. Kawano and M. Fujita, Dalton Trans., 2006, 2750-2756; d) M. Yoshizawa, J. Nakagawa, K. Kurnazawa, M. Nagao, M. Kawano, T. Ozeki and M. Fujita, Angew. Chem. Int. Ed., 2005, 44, 1810-1813.

4 a) L. J. Chen and H. B. Yang, Acc. Chem. Res., 2018, 51, 26992710; b) S. Borsley, J. A. Cooper, P. J. Lusby and S. L. Cockroft, Chem. Eur. J., 2018, 24, 4542-4546; c) H. Takezawa, T. Murase, G. Resnati, P. Metrangolo and M. Fujita, J. Am. Chem. Soc., 2014, 136, 1786-1788.

5 a) B. Therrien, Chemistry of Nanocontainers, 2012, 319, 35-55 b) O. Zava, J. Mattsson, B. Therrien and P. J. Dyson, Chem. Eur. J., 2010, 16, 1428-1431; c) J. E. M. Lewis, E. L. Gavey, S. A.
Cameron and J. D. Crowley, Chemical Science, 2012, 3, 778-784; d) A. Casini, B. Woods and M. Wenzel, Inorg. Chem., 2017, 56, 14715-14729.

6 F. J. Rizzuto, L. K. S. von Krbek and J. R. Nitschke, Nature Reviews Chemistry, 2019, 3, 204-222.

7 a) M. Iwane, T. Tada, T. Osuga, T. Murase, M. Fujita, T. Nishino, M. Kiguchi and S. Fujii, Chem. Commun., 2018, 54; b) Y. Yamauchi, M. Yoshizawa, M. Akita and M. Fujita, J. Am. Chem. Soc., 2010, 132, 960-966; c) T. Murase, K. Otsuka and M. Fujita, J. Am. Chem. Soc., 2010, 132, 7864-7865; d) N. Singh, J. H. Jo, Y. H. Song, H. Kim, D. Kim, M. S. Lah and K. W. Chi, Chem. Commun., 2015, 51, 4492-4495.

8 a) A. Sinha, F. Roelfes, A. Hepp and E. F. Hahn, Chem. Eur. J., 2017, 23, 5939-5942; b) F. M. Conrady, R. Fröhlich, C. Schulte to Brinke, T. Pape and F. E. Hahn, J. Am. Chem. Soc., 2011, 133, 11496-11499.

9 V. Martinez-Agramunt, S. Ruiz-Botella and E. Peris, Chem. Eur. J., 2017, 23, 6675-6681.

10 a) V. Martinez-Agramunt and E. Peris, Inorg. Chem., 2019, 58 11836-11842; b) V. Martinez-Agramunt, T. Eder, H. Darmandeh, G. Guisado-Barrios and E. Peris, Angew. Chem. Int. Ed., 2019, 58, 5682-5686.

11 A. J. Lowe, F. M. Pfeffer and P. Thordarson, Supramol. Chem., 2012, 24, 585-594.

12 a) E. J. Dale, N. A. Vermeulen, A. A. Thomas, J. C. Barnes, M. Juricek, A. K. Blackburn, N. L. Strutt, A. A. Sarjeant, C. L. Stern, S. E. Denmark and J. F. Stoddart, J. Am. Chem. Soc., 2014, 136, 10669-10682; b) J. C. Barnes, M. Juricek, N. L. Strutt, M. Frasconi, S. Sampath, M. A. Giesener, P. L. McGrier, C. J. Bruns, C. L. Stern, A. A. Sarjeant and J. F. Stoddart, J. Am. Chem. Soc., 2013, 135, 183-192; c) S. Ibanez and E. Peris, Angew. Chem. Int. Ed., 2019, 58, 6693-6697.

13 a) F. Cozzi, M. Cinquini, R. Annuziata and J. S. Siegel, J. Am. Chem. Soc., 1993, 115, 5330-5331; b) F. Cozzi, M. Cinquini, R. Annunziata, T. Dwyer and J. S. Siegel, J. Am. Chem. Soc., 1992, 114, 5729-5733. 